\title{
Parental longevity correlates with offspring's optimism in two cohorts of community-dwelling older subjects
}

\author{
Nathaly Rius-Ottenheim - Daan Kromhout • Anton J. M. de Craen • \\ Johanna M. Geleijnse • Roos C. van der Mast • Frans G. Zitman • \\ Rudi G. Westendorp • P. Eline Slagboom • Erik J. Giltay
}

Received: 3 August 2010 / Accepted: 10 March 2011 /Published online: 7 April 2011

(C) The Author(s) 2011. This article is published with open access at Springerlink.com

\begin{abstract}
Dispositional optimism and other positive personality traits have been associated with longevity. Using a familial approach, we investigated the relationship between parental longevity and offspring's dispositional optimism among community-dwelling older subjects. Parental age of death was assessed using structured questionnaires in two different populationbased samples: the Leiden Longevity Study $(n=1,252$, $52.2 \%$ female, mean age 66 years, $\mathrm{SD}=4$ ) and the Alpha Omega Trial $(n=769,22.8 \%$ female, mean age
\end{abstract}

N. Rius-Ottenheim $(\bowtie) \cdot$ R. C. van der Mast •

F. G. Zitman • E. J. Giltay

Department of Psychiatry,

Leiden University Medical Centre,

P.O. Box 9600, 2300RC Leiden, the Netherlands

e-mail: N.Rius_Ottenheim@lumc.nl

D. Kromhout · J. M. Geleijnse

Division of Human Nutrition, Wageningen University,

Wageningen, the Netherlands

\section{A. J. M. de Craen · R. G. Westendorp}

Department of Gerontology and Geriatrics,

Leiden University Medical Centre,

Leiden, the Netherlands

A. J. M. de Craen · R. G. Westendorp - P. E. Slagboom Netherlands Consortium for Healthy Ageing,

Leiden, the Netherlands

P. E. Slagboom

Department of Molecular Epidemiology,

Leiden University Medical Centre,

Leiden, the Netherlands
69 years, $\mathrm{SD}=6$ ). Adult offspring's dispositional optimism was assessed with the Life Orientation TestRevised (LOT-R). The association between parental age of death and levels of optimism in the offspring was analysed using linear regression analysis within each sample and a meta-analysis for the overall effect. In both samples, the parental mean age of death was positively associated with optimism scores of the offspring. The association remained significant after adjustment for age, gender, living arrangement, body mass index, smoking status, education and self-rated health of the offspring. The pooled $B$ coefficient (increase in LOT-R score per 10-year increase in parental mean age of death) was $0.30(\mathrm{SE}=0.08, p<0.001)$. In conclusion, parental longevity was positively associated with optimism in adult offspring, suggesting a partial linked heritability of longevity and optimism.

Keywords Longevity · Dispositional optimism . Personality $\cdot$ Maternal inheritance

\section{Introduction}

Human longevity is a complex trait that runs strongly in families and results from a fortunate interaction between genetic and non-genetic factors (Atzmon et al. 2004; Bocquet-Appel and Jakobi 1990; Cournil and Kirkwood 2001; Finch and Kirkwood 2000; Gudmundsson et al. 2000; Herskind et al. 1996; Hjelmborg et al. 2006; Perls et al. 2000; 
Vandenbroucke 1998). Identifying which heritable factors predict an extended life span has been an important aim of recent studies investigating longevity (Christensen et al. 2006). Although the most common design used to investigate predictors of longevity is longitudinal, an alternative design has also been proven of value in the study of predictors of longevity. This latter methodological approach is based on the hypothesis that familial patterns of longevity are linked to specific endophenotypes of the offspring (Atzmon et al. 2004; Westendorp et al. 2009). Earlier studies using a familial approach have shown that there is an association between parental longevity and indicators of cognitive functioning and well-being among the offspring (Yashin et al. 2010). Thus, a family-based approach allows exploring the association between longevity and measures of mental well-being without using the longitudinal study design of a classic prospective cohort study.

Dispositional optimism, defined as the generalized tendency to positive outcome expectations (Scheier and Carver 1985), plays an important role not only in mental health status and subjective well-being but also in physical health (Giltay et al. 2004, 2006; Scheier et al. 1994; Scheier and Carver 1985; Tindle et al. 2009). Previous results from our group have shown that dispositional optimism was associated with lower all-cause mortality after a follow-up period of 15 years (Giltay et al. 2004). Similarly, other prospective cohort studies investigating the relationship between a slightly different construct of optimism (i.e. explanatory-style optimism) and longevity found that optimism was a strong predictor of survival in college students after 40 years of follow-up (Brummett et al. 2006) and older men after 10 years of follow-up (Kubzansky et al. 2001). Also, neuroticism, a construct inversely correlated to optimism, has been negatively associated with longevity in longitudinal studies (Shipley et al. 2007; Terracciano et al. 2008; Weiss et al. 2009; Wilson et al. 2004). However, whilst these studies were conducted in a given birth cohort, the present study did not use a prospective design as longevity data from one generation were analysed in relation to the levels of optimism in the next generation (i.e. a crossgenerational association study).

The present study was conducted to examine whether parental longevity is associated with dispositional optimism in the offspring. To address this question, we evaluated the intergenerational association between parental longevity and dispositional optimism of the offspring using a family-based approach. We analysed this association in two independent samples of community-dwelling older subjects and hypothesized that long-lived parents would have a more optimistic offspring than those parents who died at an earlier age.

\section{Methods}

Study sample

This study was based on data derived from 2,021 older subjects who participated in the Leiden Longevity Study (LLS) and the Alpha Omega Trial (AOT). The study design and population characteristics of these samples have been described in detail elsewhere (Geleijnse et al. 2010; Schoenmaker et al. 2006). Briefly, in the LLS, subjects with long-lived Caucasian parents, together with their partners, were recruited to the study of predictors of longevity. Families were eligible for the study if at least two long-lived, full siblings were alive, where men were considered to be long-lived if they were 89 years or older and women if they were 91 years or older. The offspring of the long-lived subjects included in the LLS, and the offspring's partners and their parents, were also approached to participate in the LLS. This second generation (i.e. the offspring and their partners) comprised the present sample, which included a total of 2,515 subjects of the middle-aged generation with a low prevalence of cardiovascular and metabolic disease. Of these 2,515 participants of the LLS, 1,290 subjects were aged 60 years or older (range $60-$ 84 years) and 1,252 had complete data of at least one parental age of death and dispositional optimism. Of these 1,252 subjects, 880 were offspring of long-lived parents and 372 were partners of the offspring. In the AOT, 4,837 subjects aged 60-80 years with a documented history of myocardial infarction within 10 years prior to the start of the trial, thus with a high cardiovascular risk, were enrolled in the study (Geleijnse et al. 2010). Of these subjects, the last recruited 769 participants were asked to complete the Life Orientation Test (LOT-R) to measure optimism (van de Rest et al. 2008). All 769 participants who completed the optimism questionnaire provided com- 
plete information on parental age of death. All participants signed an informed consent and the studies were approved by the local medical ethics committees.

Parental vital status and age of death

Parental vital status and parental age of death were assessed through structured questionnaires in both samples. Parental vital status was subsequently categorized in "father alive", "mother alive", "both parents alive" and "both parents dead". When one or both parents were alive during the interview, the mean paternal or maternal age of death was imputed within each sample. In other words, in the LLS, an age of 86 years was imputed for maternal age of death and an age of 77 years was imputed for paternal age of death for the living parents. In the AOT, an age of 77 years was imputed for maternal age of death and an age of 72 years was imputed for paternal age of death for the living parents. Parental age of death was calculated using the mean of the maternal and paternal age of death.

\section{Dispositional optimism}

Dispositional optimism of the offspring was assessed using the LOT-R. The LOT-R is a ten-item self-report questionnaire with six items that yield an optimism score and four filler items (Scheier et al. 1994). The scale included three negatively stated items which required reverse coding before scale score computation. Subjects were asked to express the extent of their agreement with each of the items, coding their responses on a five-point Likert-type scale. The LOT-R score ranges from 0 to 24 (LLS: Cronbach's $\alpha=0.67$; AOT: Cronbach's $\alpha=0.57$ ). For the computation of the optimism scores, one missing item per subject was allowed, being subsequently imputed with the mean of the remaining five of the LOT-R. Higher scores on the LOT-R optimism scale are indicative of higher optimism levels.

Possible confounders

Socio-demographic and clinical parameters were obtained for the offspring. Living arrangement was defined as a dichotomous variable: living alone, or living with a partner or family. Education was also dichotomized into high (i.e. 11 or more years of education, with at least secondary education completed) and low education. Smoking status was classified as non-smoking, former smoking and current smoking. Body mass index (BMI) was calculated from the measured weight and height. Self-rated health was classified into feeling healthy, feeling rather unhealthy or feeling unhealthy. Only 64 participants (3.2\%) had one or more missing values on the covariables.

\section{Statistical analysis}

Socio-demographic and clinical characteristics were examined using chi-square tests for categorical variables and two-sample $t$ tests for continuous variables. These data are presented as numbers and percentages for categorical variables and means \pm standard deviations for continuous variables.

Multiple linear regression analyses were used to investigate the association between parental longevity and dispositional optimism of the offspring. We defined dispositional optimism of the offspring as our dependent variable and parental longevity as our independent variable. Unstandardized regression coefficients $(B)$ were given per 10-year increase in parental age of death. Multivariable models were applied to adjust for the effect of potential confounders. Model 1 was adjusted for age and gender of the offspring. Model 2 was additionally adjusted for living arrangement, BMI, smoking, education and self-rated health of the offspring. In addition, the association between parental age of death and dispositional optimism was assessed using a linear mixed model with a random sibship effect to model correlation of sibling data in the LLS. All $p$ values are two-tailed and considered statistically significant at the level of $p<0.05$. Data analyses were performed using SPSS for Windows, version 17.0 (Chicago, IL, USA).

Finally, we performed a meta-analysis of the data from both samples to calculate the pooled mean effect sizes (i.e. standardized mean difference) using Comprehensive Meta-analysis (version 2.2.021; Biostat, Englewood, NJ, USA). For each meta-analysis, the Cochrane's $Q$ statistics were calculated as indicators of the heterogeneity of the included studies. The pooled unstandardized regression coefficients $(B)$ were computed using fixed models as there was no evidence of heterogeneity. 


\section{Results}

Socio-demographic and clinical characteristics of both sample populations are summarized in Table 1. The mean age of the subjects from the LLS was 66 years $(\mathrm{SD}=4)$ and from the AOT was 69 years $(\mathrm{SD}=6)$. Subjects from the AOT were more likely to be men, to be living alone and to have a lower educational level than subjects from the LLS. Subjects from the AOT were also more likely to be current smokers and had a higher BMI than subjects from the LLS. Subjects from the AOT presented a higher cardiovascular risk profile due to the higher prevalence of myocardial infarction and stroke. Regarding mental well-being, optimism scores were higher among subjects from the LLS compared to subjects from the AOT. Furthermore (as expected from the inclusion criteria), parents of subjects participating in the LLS were more likely to be alive or to have died at a more advanced age. Subjects who were excluded from the analysis differed from those included in the analysis only on self-rated health, which was rated as poorer by the excluded subjects.

Results from the linear regression analysis showed that parental longevity was associated with levels of dispositional optimism in the offspring (Table 2). This association was somewhat stronger for the AOT sample, which was characterized by a higher cardiovascular risk. Multivariable adjustment for potential confounders yielded similar results. A 10-year increase in the mean age of death of the parents was associated with an increase of 0.23 point in the optimism score of the offspring in the LLS and with an increase of 0.38 point in the optimism score of the offspring in the AOT. Similar findings were found in the LLS when accounting for potential correlation of
Table 1 Baseline characteristics of the 2,021 subjects in two samples of older subjects
Data are presented as $n(\%)$, mean \pm SD. Participants had complete data on the LOT scores and the age of death of at least one of the parents LLS Leiden Longevity Study, AOT Alpha Omega Trial, $B M I$ body mass index

${ }^{a}$ The LLS and the AOT used the LOT-R to measure optimism

\begin{tabular}{|c|c|c|}
\hline & $\operatorname{LLS}(N=1,252)$ & AOT $(N=769)$ \\
\hline Age (years), mean $\pm \mathrm{SD}$ & $66.1 \pm 4.4$ & $69.2 \pm 5.7$ \\
\hline Age (years), range & $60-84$ & $60-81$ \\
\hline \multicolumn{3}{|l|}{ Gender, $n(\%)$} \\
\hline Male & $598(47.8)$ & $594(77.2)$ \\
\hline Female & $654(52.2)$ & $175(22.8)$ \\
\hline \multicolumn{3}{|l|}{ Living arrangement, $n(\%)$} \\
\hline Living with partner & $1,073(86.5)$ & $634(82.7)$ \\
\hline Other arrangement & $167(13.5)$ & $133(17.3)$ \\
\hline \multicolumn{3}{|l|}{ Education, $n(\%)$} \\
\hline Low education & $816(65.4)$ & $649(85.3)$ \\
\hline High education & $431(34.6)$ & $112(14.7)$ \\
\hline \multicolumn{3}{|l|}{ Smoking status, $n(\%)$} \\
\hline Never & 479 (38.6) & $119(15.7)$ \\
\hline Former & $627(50.6)$ & $495(65.3)$ \\
\hline Current & $134(10.8)$ & $144(19.0)$ \\
\hline BMI $\left(\mathrm{kg} / \mathrm{m}^{2}\right)$, mean $\pm \mathrm{SD}$ & $25.6 \pm 3.6$ & $27.9 \pm 4.05$ \\
\hline Poor self-rated health, $n(\%)$ & $132(10.6)$ & $198(25.9)$ \\
\hline Optimism score $^{\mathrm{a}}$, mean $\pm \mathrm{SD}$ & $15.6 \pm 3.3$ & $14.6 \pm 3.1$ \\
\hline \multicolumn{3}{|l|}{ Parents' vital status, $n(\%)$} \\
\hline Father alive & $112(9.0)$ & $5(0.7)$ \\
\hline Mother alive & $371(29.9)$ & $36(4.7)$ \\
\hline Both parents alive & $34(2.7)$ & $2(0.3)$ \\
\hline Both parents dead & $723(58.3)$ & $715(94.3)$ \\
\hline \multicolumn{3}{|c|}{ Age of death of parents (years), mean $\pm \mathrm{SD}$} \\
\hline Father & $77.9 \pm 13.9$ & $71.9 \pm 13.2$ \\
\hline Mother & $86.9 \pm 10.6$ & $77.6 \pm 13.4$ \\
\hline
\end{tabular}


Table 2 Increase in dispositional optimism scores of offspring per 10-year increase in parental age of death

\begin{tabular}{|c|c|c|c|c|c|c|c|c|c|}
\hline & \multicolumn{3}{|l|}{ LLS } & \multicolumn{3}{|l|}{ AOT } & \multicolumn{3}{|l|}{ Overall } \\
\hline & $B(\mathrm{SE})$ & $t$ test & $p$ value & $B(\mathrm{SE})$ & $t$ test & $p$ value & $B(\mathrm{SE})$ & $p$ value & Cochrane's $Q$ ( $p$ value) \\
\hline \multicolumn{10}{|c|}{ Mean age of death of both parents (per 10 years) } \\
\hline Model 1 & $0.267(0.103)$ & 2.595 & 0.01 & $0.420(0.113)$ & 3.723 & $<0.001$ & $0.336(0.076)$ & $<0.001$ & $1.001(0.32)$ \\
\hline Model 2 & $0.233(0.102)$ & 2.284 & 0.02 & $0.378(0.113)$ & 3.337 & 0.001 & $0.298(0.076)$ & $<0.001$ & $0.907(0.34)$ \\
\hline \multicolumn{10}{|c|}{ Mean age of death of father (per 10 years) } \\
\hline Model 1 & $0.153(0.070)$ & 2.178 & 0.03 & $0.150(0.084)$ & 1.774 & 0.08 & $0.152(0.054)$ & 0.005 & $0.001(0.98)$ \\
\hline Model 2 & $0.126(0.070)$ & 1.795 & 0.07 & $0.137(0.085)$ & 1.625 & 0.11 & $0.130(0.054)$ & 0.02 & $0.010(0.92)$ \\
\hline \multicolumn{10}{|c|}{ Mean age of death of mother (per 10 years) } \\
\hline Model 1 & $0.133(0.083)$ & 1.596 & 0.11 & $0.298(0.084)$ & 3.555 & $<0.001$ & $0.215(0.059)$ & $<0.001$ & $1.952(0.16)$ \\
\hline Model 2 & $0.139(0.082)$ & 1.693 & 0.09 & $0.271(0.083)$ & 3.265 & 0.001 & $0.204(0.058)$ & $<0.001$ & $1.280(0.26)$ \\
\hline
\end{tabular}

Results are given as unstandardized $B$ coefficients by linear regression analysis (with accompanying $p$ values) per 10-year increase in parental mean age of death

Model 1: adjusted for age and gender of the offspring. Model 2: additionally adjusted for living arrangement, body mass index, smoking, education and self-rated health of the offspring

LLS Leiden Longevity Study, AOT Alpha Omega Trial

${ }^{\text {a }}$ Meta-analysis of the data from the two samples to yield the pooled $B$ coefficients using a fixed effects model

sibling data in a multilevel analysis (data not shown). Furthermore, the results showed that paternal and maternal age of death made an additional contribution to the optimism levels of the offspring; however, in both samples, the contribution of the age of death of the mother was somewhat stronger than that of the father (Table 2).

The results in Table 2 are graphically presented in Fig. 1. This figure shows that an increase of the parental mean age of death is positively associated with the dispositional optimism scores of the offspring in both samples, with a somewhat stronger association observed for the AOT sample of postmyocardial infarction patients.

In addition, several sensitivity analyses were conducted to examine the association in a number of situations that may have affected our findings. First, we excluded 35 participants who had lost their parents before their $20 \mathrm{~s}$ and subsequently excluded 583 participants with at least one living parent. The results from these analyses showed that, also in these cases, parental age of death was correlated to the dispositional optimism levels of the offspring, indicating that adverse childhood life events were not the driving factor for the association under study. An additional sensitivity analysis in the LLS sample showed that the loss of a parent within the preceding 6 months also did not affect our findings, thus reducing the possibility that grief reactions accounted for lower scores of optimism in the offspring. Similarly, the gender of the last surviving parent had no effect on our results. Next, when analysing whether associations differed between sons and daughters, we found that among sons, the association was somewhat stronger, although the appropriate interaction term was not significant. Finally, imputation of the actual parental age at the moment of the interview in the case of parents who were still alive in the LLS resulted in persistence of a significant association between parental longevity and offspring's optimism (data not shown).

Results from the meta-analysis showed an overall association between parental longevity and the offspring's optimism scores (Table 2). A 10-year increase in the overall parental mean age of death was associated with an increase of $0.30 \mathrm{SD}$ in the dispositional optimism scores of the offspring.

\section{Discussion}

Our results show a positive association between parental longevity and dispositional optimism of the offspring. In other words, our findings indicate that long-lived parents tended to have more optimistic offspring, independently of potential confounders. Longevity of both the father and the mother contributed to the 


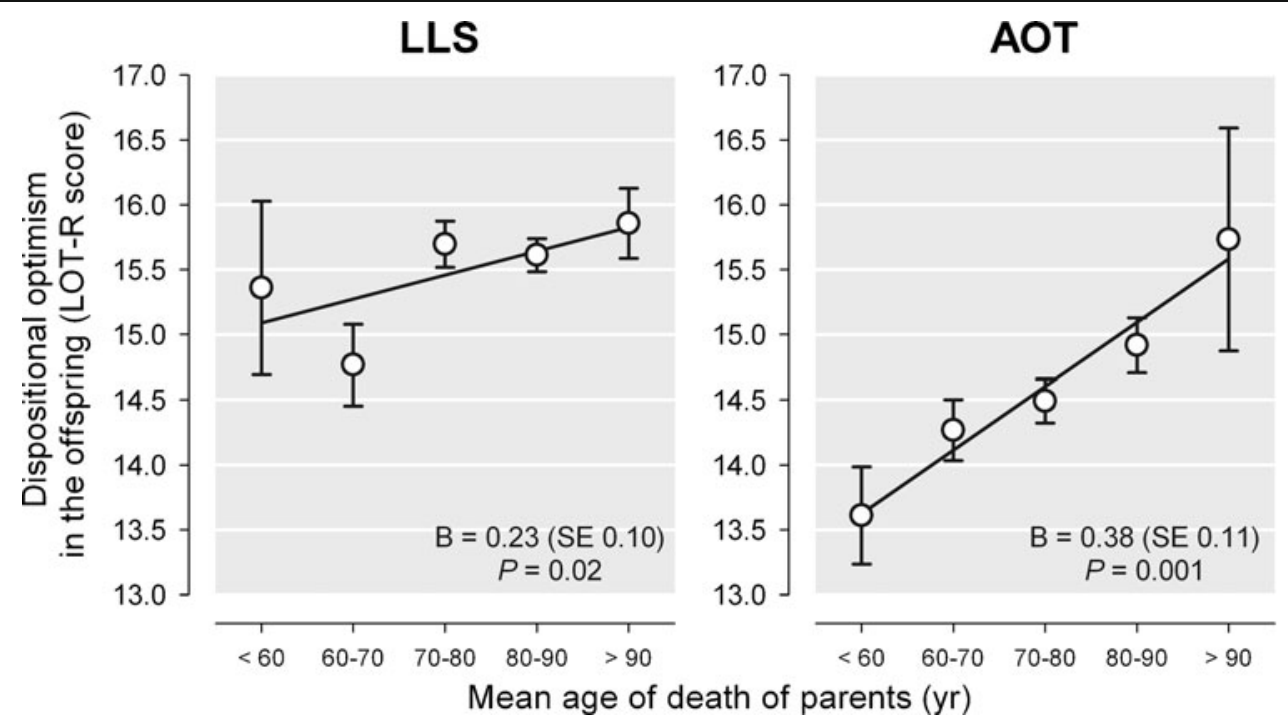

Fig. 1 Dispositional optimism of the offspring according to categories of the mean age of death of both parents (i.e. parental longevity). Univariate regression lines are shown with unstandardized $B$ coefficients analysed by linear regression analysis

association with dispositional optimism of the offspring. Thus, our results suggest that longevity and dispositional optimism may be intergenerationally associated, based on a design that has been used previously (Martin et al. 2007; Perls and Terry 2003; Yashin et al. 2010)

An important strength of our study was the consistency of our results in two independent samples of community-dwelling old subjects. Furthermore, this analysis in two different samples allowed us to compare the association between longevity and offspring's endophenotypes in a sample with exceptional long-lived family members with a low cardiovascular risk (LLS) to that found in another sample of post-myocardial infarction patients with families with average life spans (AOT).

However, some limitations of the study need to be considered. First, the causal direction of the association remains unclear. Second, the findings might reflect ethnicity-specific effects and should therefore be confirmed in other non-Caucasian populations. Third, it should be noted that about a quarter of the LLS subjects were sibling pairs, therefore not independent as they shared the same mean age of death of their parents. However, our findings did not change substantially when we accounted for sibling correlation in a linear mixed model analysis. Fourth, because participants in the LLS were selected for longevity of the participants and their sibs, the variability under (per 10-year increase in age of death), adjusted for age, gender, living arrangement, body mass index, smoking, education and self-rated health of the offspring

study in the variables optimism and longevity of the parents might be reduced. This potentially reduced variability may explain the somewhat weaker associations in the LLS as compared to the AOT. Finally, recall bias may have arisen as the level of offspring's optimism may have overestimated the actual age of death of the parents.

To our knowledge, our study is the first to consider the association between parental longevity and offspring's dispositional optimism. Findings from the present study are consistent with the previously described cross-sectional study (Yashin et al. 2010), which also used a familial approach and showed that parental longevity was associated with certain endophenotypic characteristics of the offspring, such as cognition. Using a similar study design, we extend these findings by showing that parental longevity is also associated with personality traits of the offspring. Our findings are also in accordance with a study among 246 centenarians which found that the offspring had lower levels of neuroticism and higher extraversion compared to norm scores (Givens et al. 2009). The present findings also extend previous results of our group and others which showed, in the same generation, a positive association between dispositional optimism and lower (cardiovascular) mortality rates (Chida and Steptoe 2008; Giltay et al. 2004, 2006; Tindle et al. 2009). 
Although our results show an association between longevity and optimism in two different samples, the underlying mechanisms for this association remain to be elucidated. The association between parental longevity and offspring's optimism may be explained by genetic factors, environmental factors or a combination of both. Previous family studies have indicated that the two phenotypes, longevity and dispositional optimism, have a heritable component and may be part of a phenotypical spectrum that is inherited together (Martin et al. 2007; Plomin et al. 1992). However, shared heritability is only one of the multiple potential mechanisms, and the environmental effects should not be underestimated. An increasing body of evidence shows that certain factors in childhood environment, particularly the presence of resources such as parental warmth and financial security, may act as a determinant of both parental longevity and offspring's optimism (Heinonen et al. 2005, 2006). For instance, offspring may resemble their parents in their health-promoting behaviours, such as smoking habits, alcohol use, dietary patterns and physical activity (Repetti et al. 2002; Zhang et al. 2004), arising through the effects of reflection and learning. Moreover, this mirroring effect may also influence the offspring's coping styles and stress reactivity to adverse life events. Alternatively, the offspring's optimism may affect longevity of the parents through increased social support and maintenance of the parental role. In this way, offspring's support may buffer parental distress by mediating environmental stresses that threaten to overwhelm the coping abilities of the older parent (Okamoto and Tanaka 2004; Silverstein and Bengtson 1991; Zunzunegui et al. 2009).

In our study, optimism levels of the offspring were the highest when both parents were longlived. However, maternal longevity was slightly more strongly associated with offspring's optimism than paternal longevity. These findings are consistent with the results of some studies that investigated the relative importance of the sex-specific transmission of heritable factors on longevity (Brand et al. 1992; Yashin et al. 2010). The authors suggested that the stronger effect of maternal longevity on offspring's characteristics might be primarily mediated through shared heritable factors, either genetic or non-genetic (Brand et al. 1992). Nevertheless, environmental factors are also likely to play an important role in the differential inheritance of longevity. Either way, potential recall biases should also be taken into account when evaluating sex-specific differences in longevity as it is possible that interviewed participants may better recall their mothers' than their fathers' life span.

In conclusion, our findings suggest that parental longevity, particularly maternal longevity, is associated with offspring's dispositional optimism. These results may help in understanding the mechanisms of familiar transmission of human longevity and the role of optimism. However, further studies are warranted to disentangle the potential causal relationships between life span and dispositional optimism.

Acknowledgements The Leiden Longevity Study was funded by the Innovation Oriented Research Program on Genomics (Senter Novem; IGE01014 and IGE5007), the Centre for Medical Systems Biology, the Netherlands Genomics Initiative/Netherlands Organization for scientific research (05040202 and 050-060-810) and the European Union-funded Network of Excellence Lifespan (FP6 036894). The Alpha Omega Trial was supported by The Netherlands Heart Foundation (grant no. 2000T401), US National Institutes of Health (NIH/NHLBI and ODS, grant no. R01HL076200) and Unilever RandD, Vlaardingen.

Open Access This article is distributed under the terms of the Creative Commons Attribution Noncommercial License which permits any noncommercial use, distribution, and reproduction in any medium, provided the original author(s) and source are credited.

\section{References}

Atzmon G, Schechter C, Greiner W, Davidson D, Rennert G, Barzilai N (2004) Clinical phenotype of families with longevity. J Am Geriatr Soc 52(2):274-277

Bocquet-Appel J, Jakobi L (1990) Familial transmission of longevity. Ann Hum Biol 17(2):81-95

Gudmundsson H, Gudbjartsson D, Frigge M, Gulcher J, Stefansson K (2000) Inheritance of human longevity in Iceland. Eur J Hum Genet 8(10):743-749

Herskind A, McGue M, Holm N, Sorensen T, Harvald B, Vaupel J (1996) The heritability of human longevity: a population-based study of 2872 Danish twin pairs born 1870-1900. Hum Genet 97(3):319-323

Hjelmborg J, Iachine I, Skytthe A, Vaupel J, McGue M, Koskenvuo M, Kaprio J, Pedersen N, Christensen K (2006) Genetic influence on human lifespan and longevity. Hum Genet 119(3):312-321

Perls T, Shea-Drinkwater M, Bowen-Flynn J, Ridge S, Kang S, Joyce E, Daly M, Brewster S, Kunkel L, Puca A (2000) Exceptional familial clustering for extreme longevity in humans. J Am Geriatr Soc 48(11):1483-1485

Vandenbroucke J (1998) Maternal inheritance of longevity. Lancet 351(9108):1064 
Cournil A, Kirkwood T (2001) If you would live long, choose your parents well. Trends Genet 17(5):233-235

Finch C, Kirkwood T (2000) Chance, development and aging. Oxford University Press, Oxford

Christensen K, Johnson T, Vaupel J (2006) The quest for genetic determinants of human longevity: challenges and insights. Nat Rev Genet 7(6):436-448

Westendorp R, van Heemst D, Rozing M, Frolich M, Mooijaart S, Blauw G, Beekman M, Heijmans B, de Craen A, Slagboom P (2009) Nonagenarian siblings and their offspring display lower risk of mortality and morbidity than sporadic nonagenarians: the Leiden Longevity Study. J Am Geriatr Soc 57(9):1634-1637

Yashin A, Arbeev K, Kulminski A, Borecki I, Christensen K, Barmada M, Hadley E, Rossi W, Lee J, Cheng R, Elo I (2010) "Predicting" parental longevity from offspring endophenotypes: data from the Long Life Family Study (LLFS). Mech Ageing Dev 131(3):215-222

Scheier M, Carver C (1985) Optimism, coping, and health: assessment and implications of generalized outcome expectancies. Health Psychol 4(3):219-247

Scheier MF, Carver CS, Bridges MW (1994) Distinguishing optimism from neuroticism (and trait anxiety, self-mastery, and self-esteem): a reevaluation of the Life Orientation Test. J Pers Soc Psychol 67(6):1063-1078

Giltay E, Geleijnse J, Zitman F, Hoekstra T, Schouten E (2004) Dispositional optimism and all-cause and cardiovascular mortality in a prospective cohort of elderly Dutch men and women. Arch Gen Psychiatry 61(11):1126-1135

Giltay E, Kamphuis M, Kalmijn S, Zitman F, Kromhout D (2006) Dispositional optimism and the risk of cardiovascular death: the Zutphen Elderly Study. Arch Intern Med 166(4):431-436

Tindle H, Chang Y, Kuller L, Manson J, Robinson J, Rosal M, Siegle G, Matthews K (2009) Optimism, cynical hostility, and incident coronary heart disease and mortality in the Women's Health Initiative. Circulation 120(8):656-662

Brummett B, Helms M, Dahlstrom W, Siegler I (2006) Prediction of all-cause mortality by the Minnesota Multiphasic Personality Inventory Optimism-Pessimism Scale scores: study of a college sample during a 40-year followup period. Mayo Clin Proc 81(12):1541-1544

Kubzansky LD, Sparrow D, Vokonas P, Kawachi I (2001) Is the glass half empty or half full? A prospective study of optimism and coronary heart disease in the normative aging study. Psychosom Med 63(6):910-916

Shipley B, Weiss A, Der G, Taylor M, Deary I (2007) Neuroticism, extraversion, and mortality in the UK Health and Lifestyle Survey: a 21-year prospective cohort study. Psychosom Med 69(9):923-931

Terracciano A, Lockenhoff C, Zonderman A, Ferrucci L, Costa PJ (2008) Personality predictors of longevity: activity, emotional stability, and conscientiousness. Psychosom Med 70(6):621-627

Weiss A, Gale C, Batty G, Deary I (2009) Emotionally stable, intelligent men live longer: the Vietnam Experience Study cohort. Psychosom Med 71(4):385-394
Wilson R, Mendes de Leon C, Bienias J, Evans D, Bennett D (2004) Personality and mortality in old age. J Gerontol B Psychol Sci Soc Sci 59(3):110-116

Schoenmaker M, de Craen A, de Meijer P, Beekman M, Blauw G, Slagboom P, Westendorp R (2006) Evidence of genetic enrichment for exceptional survival using a family approach: the Leiden Longevity Study. Eur J Hum Genet 14(1):79-84

Geleijnse J, Giltay E, Schouten E, de Goede J, Griep L, TeitsmaJansen A, Katan M, Kromhout D (2010) Effect of low doses of $n-3$ fatty acids on cardiovascular diseases in 4,837 postmyocardial infarction patients: design and baseline characteristics of the Alpha Omega Trial. Am Heart J 159(4):539-546

van de Rest O, Geleijnse J, Kok F, van Staveren W, Dullemeijer C, Olderikkert M, Beekman A, de Groot C (2008) Effect of fish oil on cognitive performance in older subjects: a randomized, controlled trial. Neurology 71(6):430-438

Martin G, Bergman A, Barzilai N (2007) Genetic determinants of human health span and life span: progress and new opportunities. PLoS Genet 3(7):e125

Perls T, Terry D (2003) Understanding the determinants of exceptional longevity. Ann Intern Med 139(5 Pt 2):445-449

Givens J, Frederick M, Silverman L, Anderson S, Senville J, Silver M, Sebastiani P, Terry D, Costa P, Perls T (2009) Personality traits of centenarians' offspring. J Am Geriatr Soc 57(4):683-685

Chida Y, Steptoe A (2008) Positive psychological well-being and mortality: a quantitative review of prospective observational studies. Psychosom Med 70(7):741-756

Plomin R, Scheier M, Bergeman C, Pedersen N, Nesselroade J, McClearn G (1992) Optimism, pessimism and mental health: a twin/adoption analysis. Pers Indiv Diffs 13:921-930

Heinonen K, Raikkonen K, Keltikangas-Jarvinen L (2005) Dispositional optimism: development over 21 years from the perspective of perceived temperament and mothering. Pers Indiv Diffs 38:425-435

Heinonen K, Raikkonen K, Matthews K, Scheier M, Raitakari O, Pulkki L, Keltikangas-Jarvinen L (2006) Socioeconomic status in childhood and adulthood: associations with dispositional optimism and pessimism over a 21-year follow-up. J Pers 74(4):1111-1126

Repetti R, Taylor S, Seeman T (2002) Risky families: family social environments and the mental and physical health of offspring. Psychol Bull 128(2):330-366

Zhang J, Lu Y, Qiu X, Fang Y (2004) Relationship between alcohol drinking and alcohol-related health problems. Biomed Environ Sci 17(2):196-202

Silverstein M, Bengtson V (1991) Do close parent-child relations reduce the mortality risk of older parents? J Health Soc Behav 32(4):382-395

Okamoto K, Tanaka Y (2004) Subjective usefulness and 6-year mortality risks among elderly persons in Japan. J Gerontol B Psychol Sci Soc Sci 59(5):246-249

Zunzunegui M, Beland F, Sanchez M, Otero A (2009) Longevity and relationships with children: the importance of the parental role. BMC Public Health 9:351

Brand F, Kiely D, Kannel W, Myers R (1992) Family patterns of coronary heart disease mortality: the Framingham Longevity Study. J Clin Epidemiol 45(2):169-174 